\title{
A Psyllid, Boreioglycaspis melaleucae Moore (Insecta: Hemiptera: Psyllidae) ${ }^{1}$
}

\author{
Susan A. Wineriter, Susan E. Halbert and James P. Cuda²
}

\section{Introduction}

The introduced tree Melaleuca quinquenervia (Cav.) S.T. Blake (Myrtaceae), known as paperbark, punktree or melaleuca, is an aggressive invader of many South Florida ecosystems, including the Everglades. Melaleuca is considered a pest because it displaces native vegetation and degrades wildlife habitat; it also creates fire hazards and can cause human health problems (Rayamajhi et al. 2002). The USDA/ARS with federal and state permission introduced the psyllid Boreioglycaspis melaleucae (Figure 1) into Broward County, Florida, in February 2002 as a potential biocontrol agent of melaleuca.

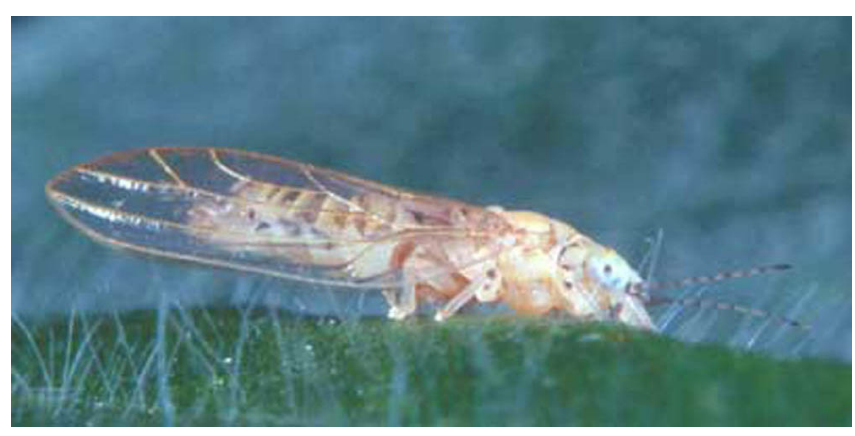

Figure 1. Adults of Boreioglycaspis melaleucae Moore, a psyllid. Credits: Susan Wineriter, USDA

\section{Distribution}

B. melaleucae has been collected from all states in its native Australia except South Australia (Burkhardt 1991). Specimens released in Florida originated from southeastern Queensland. As of October 2002, the melaleuca psyllid had been released in five Florida counties: Broward, Collier, Lee, Miami-Dade and Palm Beach, and is known to have established in all counties except Palm Beach. It will be introduced or spread naturally to all 22 central and south Florida counties where melaleuca infestations occur.

\section{Description}

\section{Adults}

Boreioglycaspsis adults (Figure 2) are small, about $3 \mathrm{~mm}$ long, and inconspicuous, pale yelloworange to white in color with gray to black markings. The tips of the antennae are gray to black and the wings are transparent with yellow veins. The compound eyes are usually pale green with a distinctive dark spot within, but various shades of red have been observed in the laboratory; its three ocelli

1. This document is EENY-300 (originally published as DPI Entomology Circular 410- updated for this publication), one of a series of Featured Creatures from the Entomology and Nematology Department, Florida Cooperative Extension Service, Institute of Food and Agricultural Sciences, University of Florida. Published: August 2003. This document is also available on Featured Creatures Website at http://creatures.ifas.ufl.edu. Please visit the EDIS Website at http://edis.ifas.ufl.edu.

2. Susan A. Wineriter, USDA; Susan E. Halbert, Florida Department of Agriculture and Consumer Services, Division of Plant Industry; and James P. Cuda, Entomology and Nematology Department, University of Florida, Gainesville, FL

The Institute of Food and Agricultural Sciences is an equal opportunity/affirmative action employer authorized to provide research, educational information and other services only to individuals and institutions that function without regard to race, color, sex, age, handicap, or national origin. For information on obtaining other extension publications, contact your county Cooperative Extension Service office. Florida Cooperative Extension Service/Institute of Food and Agricultural Sciences/University of Florida/Christine Taylor Waddill, Dean. 
are bright orange, the dorsal two being the most obvious. Two prominent finger-shaped appendages or genae (Figure 3) extend outward and slightly downward from beneath the eyes. When resting or feeding, the body is parallel to leaf or stem surfaces unlike, for example, the invasive Asian citrus psyllid, Diaphorina citri, that holds its body at a $45^{\circ}$ angle.

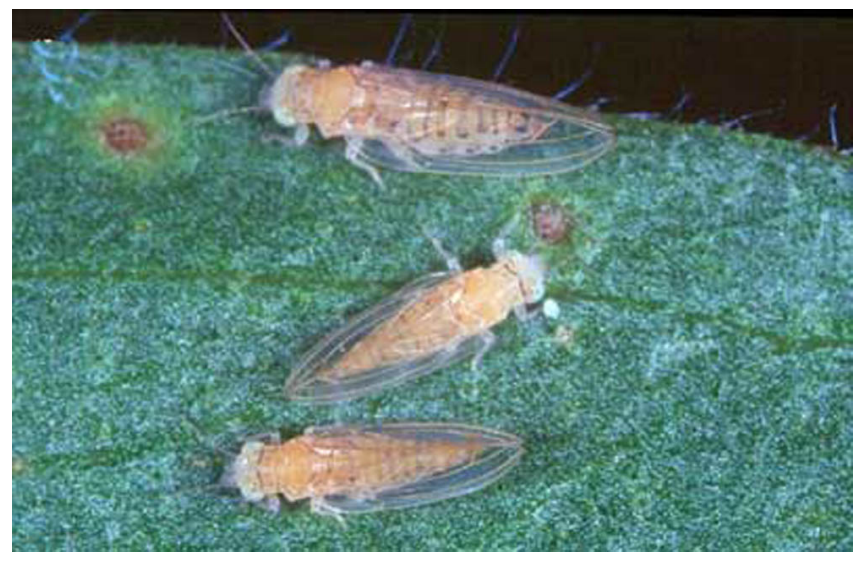

Figure 2. Adults of Boreioglycaspis melaleucae Moore, a psyllid. Credits: Susan Wineriter, USDA

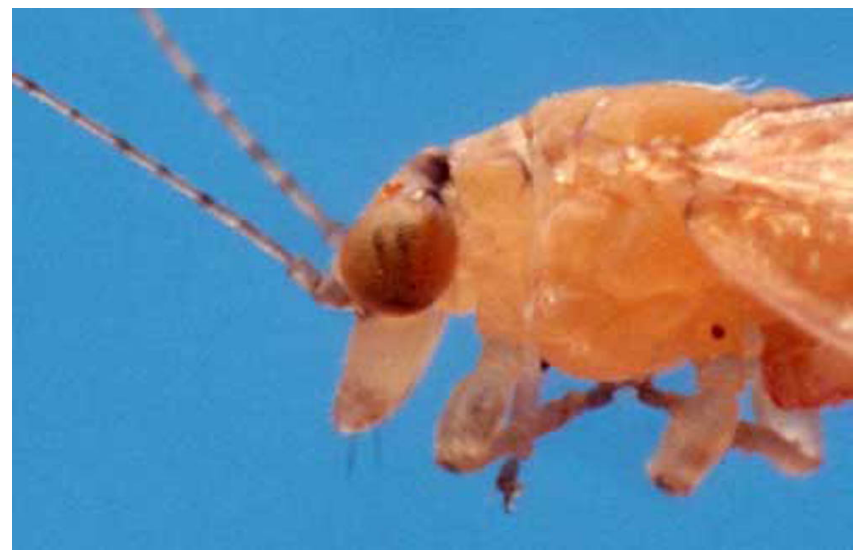

Figure 3. Lateral view of the gena of Boreioglycaspis melaleucae Moore, a psyllid. Credits: Jeffrey Lotz, DPI

Males and females can be distinguished easily from one another by the shape of their abdomens and by the male genitalia. The abdomen of a male is shaped like an elongated isosceles triangle when viewed from above and terminates in distinctive claspers, easily apparent when viewed laterally. The abdomen of a female is more rectangular, gradually tapering to the tip; the pleural membranes usually are expanded, partially visible from above, bulging with eggs. Females generally are larger than males. Adults frequently drag their hind legs when walking, and jump or fly when disturbed.

\section{Nymphs}

Nymphs, except for neonates (or newly hatched insects), are sedentary unless disturbed. First instars are pale yellow with no markings, but by the 5th instar they have gray to black markings on the body (Figure 4). Nymphs secrete conspicuous white waxy filaments from a dorsal caudal plate while feeding. The filamentous wax loosely covers their bodies (Figure 5). Branches and leaves become covered with the waxy filaments creating a flocculence (wool-like tufts) that indicates a heavy infestation (Figure 6). Rain will wash away the flocculence, but nymphs will soon secrete more. In addition, they produce copious amounts of honeydew held externally in balloon-like waxy membranes; nymphs discard honeydew filled spheres nearby. Adults also excrete waxy spheres of honeydew, but they flip them away from their immediate area.

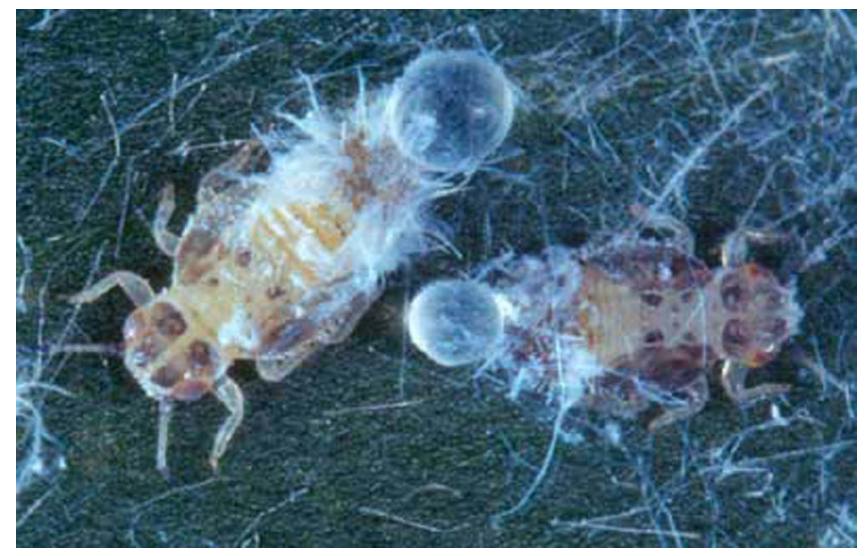

Figure 4. Older nymphs of Boreioglycaspis melaleucae Moore, a psyllid, secreting honeydew. Waxy flocculence has been brushed away. Credits: Jeffrey Lotz, DPI

\section{Eggs}

Eggs are pale to bright yellow and are laid singly or in groups on both leaves and stems of melaleuca (Figure 7). They are held on by a narrow projection or pedicel inserted into the leaf.

\section{Life History}

Seasonal occurrence of B. melaleucae in Australia or Florida has not been documented yet. In Australia, "congregations of nymphs frequently were observed among the tightly bound leaves of young shoots" (Purcell et al. 1997). Laboratory observations indicate that under South Florida conditions, it should 


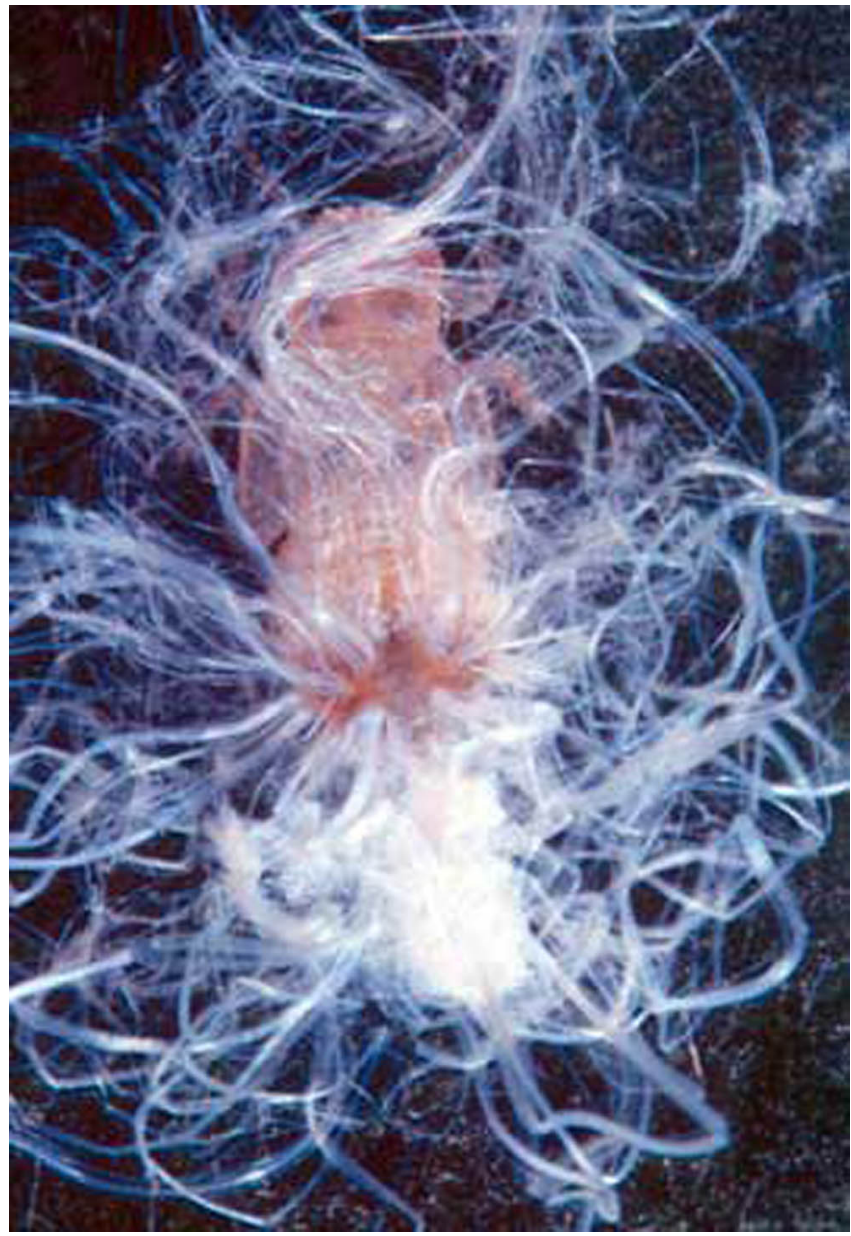

Figure 5. Nymph of Boreioglycaspis melaleucae Moore, a psyllid, exuding filamentous wax strands. Credits: Susan Wineriter, USDA

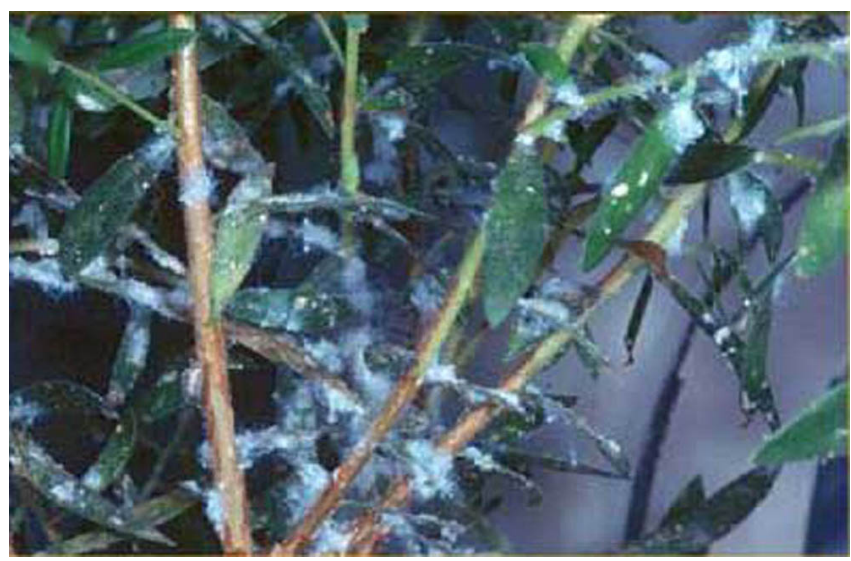

Figure 6. Melaleuca stems and leaves covered with a white waxy flocculence produced by a heavy infestation of nymphs of Boreioglycaspis melaleucae Moore, a psyllid. Credits: Susan Wineriter, USDA

reproduce year-round. Populations will be more abundant when melaleuca plants are in a growth phase (late fall through spring). At 25 to $27^{\circ} \mathrm{C}$ in the laboratory, the melaleuca psyllid completed its

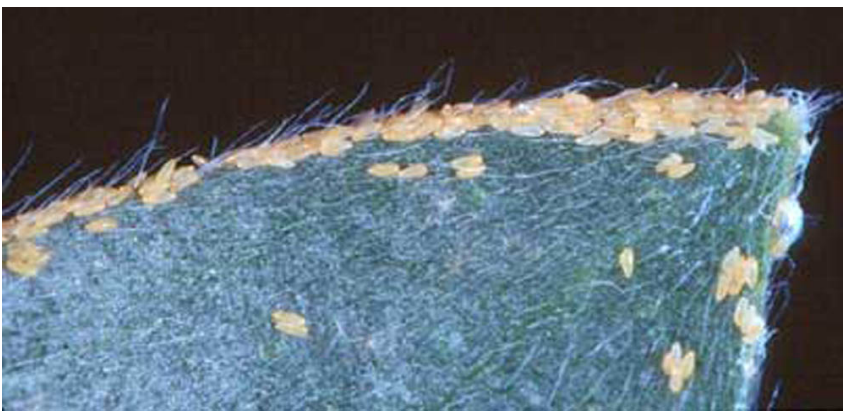

Figure 7. Eggs of Boreioglycaspis melaleucae Moore, a psyllid, on tip of a melaleuca leaf. Credits: Susan Wineriter, USDA

life cycle in about six to seven weeks. Females had a short pre- oviposition period, a day or less, and mated throughout the day. Females deposit approximately 80 eggs (Rayamajhi et al. 2002), and the eggs hatch in two to three weeks. The nymphal stage (five instars) lasted three to four weeks.

\section{Importance}

Both adults and nymphs fed on melaleuca, but nymphal feeding severely damaged melaleuca. Leaves became chlorotic, turned brown and eventually died. Heavy infestations killed young plants and saplings. The melaleuca snout weevil, Oxyops vitiosa, the first insect released for biological control of melaleuca, cannot establish at permanently flooded melaleuca sites because of the soil requirement for pupation. Under these conditions, the psyllid B. melaleucae should still be capable of severely damaging melaleuca because this insect completes its life cycle entirely in the tree canopy.

\section{Hosts}

In Australia, B. melaleucae is known to occur on four species of closely related melaleucas in the Melaleuca leucadendra complex. These are Melaleuca argentea, Melaleuca leucadendra, Melaleuca nervosa, and Melaleuca quinquenervia. None of these species is native to the New World. In addition, in host range studies conducted at the USDA/ARS Australian Biological Control Laboratory, it completed development on Melaleuca viridiflora and Melaleuca nodosa, also native to Australia. In host-range tests conducted at the FDACS Florida Biological Control Laboratory, it completed development one time on bottlebrush, 
Callistemon (= Melaleuca) citrinus, the broad-leaved form, an introduced ornamental.

\section{Survey and Detection}

In order to survey for B. melaleucae, look for flocculence on the newest growth of the host trees. Adults can be collected using a beat sheet and an insect aspirator or with yellow sticky insect trapping cards.

\section{Similar Species in Florida}

Boreioglycaspis melaleucae is distinctive because of its long genae (Figure 8), which are nearly as long as the vertex. The only other species in Florida with such conspicuous long genae is the invasive pest species, Glycaspis brimblecombei Moore, found on introduced Eucalyptus (Halbert et al. 2001). When alive, the green color morph (Figure 9) would not be confused with $B$. melaleucae, but the brown color morph (Figure 10) could be. When dead, G. brimblecombei color morphs are more similar and both could be confused with $B$. melaleucae.

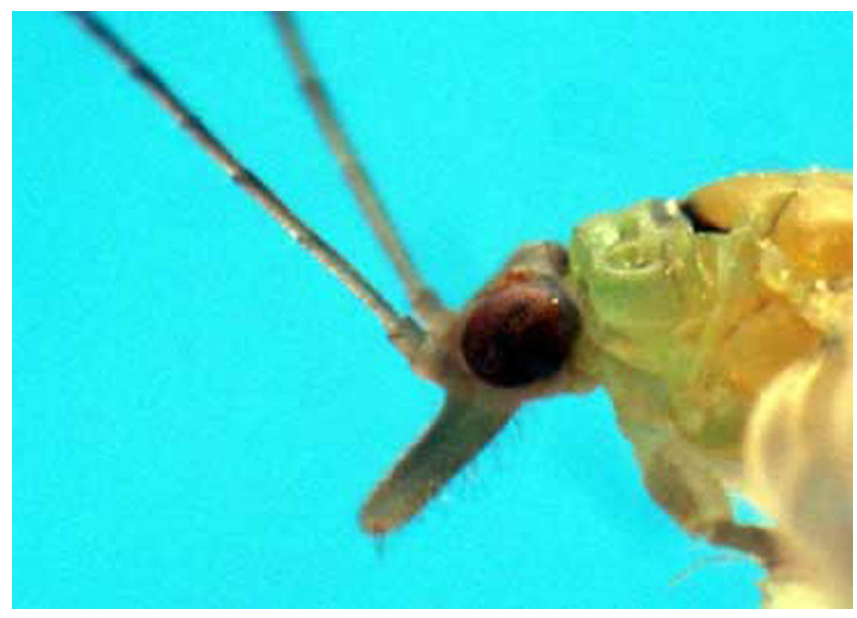

Figure 8. Lateral view of the gena of Boreioglycaspis brimblecombei Moore, a psyllid. Credits: Jeffrey Lotz, DPI

Dead adults can be separated by the following couplet:

1. Antennae less than half as long as body, excluding wings; branch of the median wing vein distal to the point at which $\mathrm{Cu} 1 \mathrm{a}$ intersects the edge of the wing ........ melaleucae

1 '. Antennae about 3/4 as long as body, excluding wings; branch of median wing vein

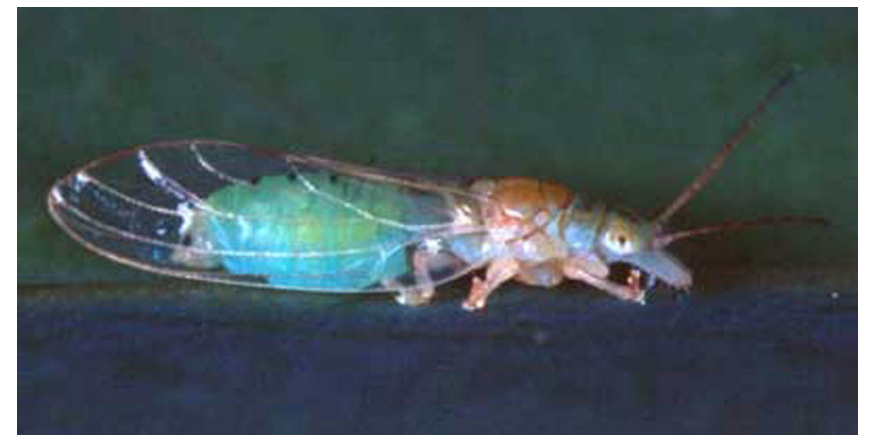

Figure 9. Female green color morph of Glycaspis brimblecombei Moore, a psyllid. Credits: Susan Wineriter, USDA

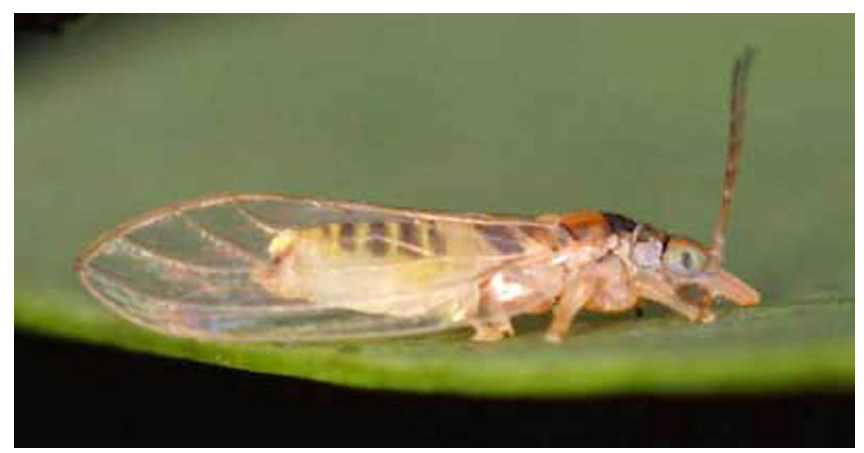

Figure 10. Female brown color morph of Glycaspis brimblecombei Moore, a psyllid. Credits: Susan Wineriter, USDA

proximal to the point at which $\mathrm{Cu} 1 \mathrm{a}$ intersects the edge of the wing ....... G. brimblecombei

Nymphs should not be confused on plants: Glycaspis brimblecombei nymphs form lerps (a shelter produced from a carbohydrate secretion from the anus), whereas $B$. melaleucae nymphs are just covered with fuzzy wax. Another introduced but not invasive psyllid, Blastopsylla occidentalis Taylor, found on introduced eucalpytus, is morphologically quite distinctive from $B$. melaleucae, but the overall appearance of the adult and similar nymphal flocculence could cause confusion. This psyllid is about half the size of B. melaleucae and has no prominent genae.

\section{Management}

\section{Biological Control}

The psyllid should be a major pest of Melaleuca quinquenervia only; and therefore, there should be no need for biological control. One Australian nymphal parasitoid, Psyllaephagus sp., (Hymenoptera: Encyrtidae) is known from B. melaleucae (Purcell et 


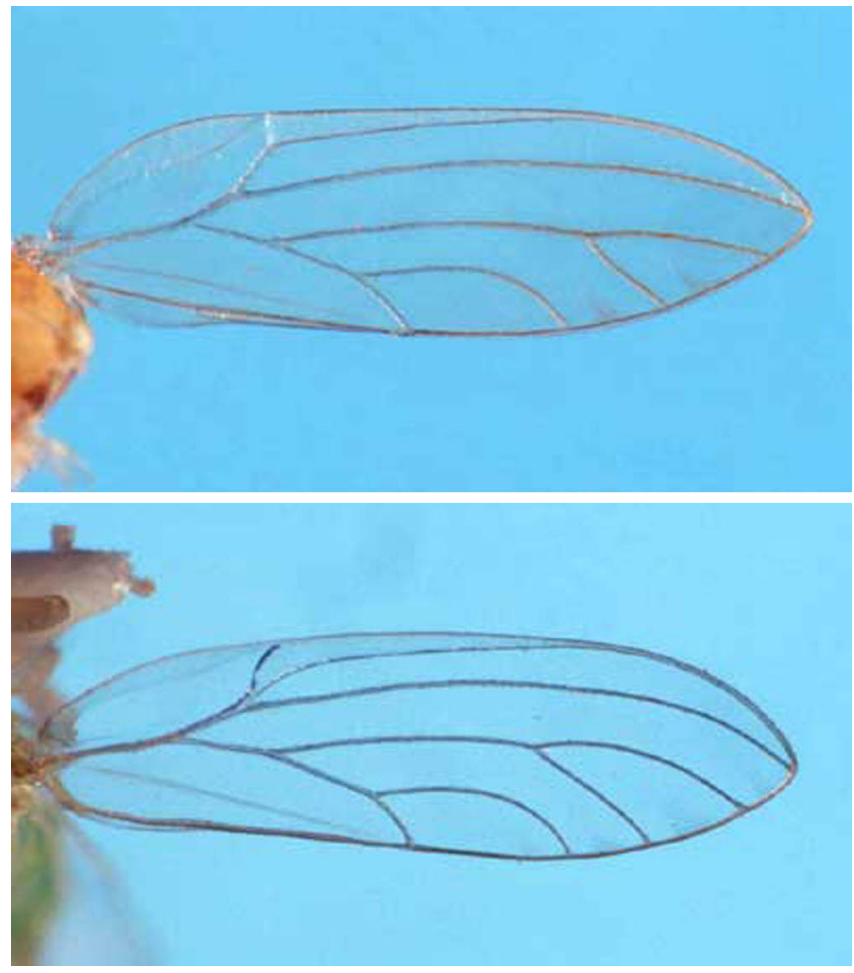

Figure 11. Hind wing of Boreioglycaspis melaleucae Moore, a psyllid (top). Hind wing of Glycaspis brimblecombei Moore, a psyllid (bottom). Credits: Susan Wineriter, USDA

al. 1997) and was screened out of shipments sent to Florida. No Psyllaephagus spp. occur in Florida, and native Florida psyllid parasites are unlikely to cross-over.

\section{Chemical Control}

Melaleuca quinquenervia is a federally and state-listed noxious weed and legally cannot be purchased or possessed. However, landowners of older large melaleuca trees in urban areas may be distressed by the damage psyllids cause to their trees or by the abundance of flocculence and honeydew produced by nymphs. While homeowners should be encouraged to remove trees, they may not be willing to do so. Chemicals labeled for psyllids may be warranted in this instance. Strong sprays of water will wash the nymphs from the leaves.

\section{Selected References}

Burckhardt D. 1991. Boreioglycaspis and spondyliaspidine classification (Homoptera: Psylloidea). The Raffles Bulletin of Zoology 39: 15-52.
Halbert SE, Gill RJ, Nisson JN. 2001. Two Eucalyptus psyllids new to Florida (Homoptera: Psyllidae). Florida Department of Agriculture \& Consumer Services, Division of Plant Industry, Gainesville, Entomology Circular No. 407: 1-2.

Hodkinson I D. 1974. The biology of Psylloidea (Homoptera): a review. Bulletin of Entomological Research 64: 325-339.

Moore KM. 1964. Observations of some Australian forest insects. 19. Additional information on the genus Glycaspis (Homoptera: Psyllidae); erection of a new subgenus and descriptions of six new species. Proceedings of the Linnean Society of New South Wales 89: 221-234.

Moore KM. 1970. Observations of some Australian forest insects. 23. A revision of the genus Glycaspsis (Homoptera: Psyllidae) with descriptions of seventy-three new species. Australian Zoologist 15: 248-342.

Purcell MR, Balciunas JK, Jones P. 1997. Biology and host-range of Boreioglycaspis melaleucae (Hemiptera: Psyllidae), potential biological control agent for Melaleuca quinquenervia (Myrtaceae). Environmental Entomology 26: 366-372.

Rayamajhi MB, Purcell MF, Van TK, Center TD, Pratt PD, Buckingham GR. 2002. Australian paperbark tree (Melaleuca), pp. 117-130. In Van Driesche R, Blossey B, Hoddle M, Lyon S, and Reardon R (eds.), Biological Control of Invasive Plants in the Eastern United States. USDA Forest Service Publication FHTET-2002-04. USDA Forest Service, Morgantown, West Virginia.

Wineriter SA, Buckingham GR, Frank JH. 2003. Host-range of Boreioglycaspis melaleucae Moore (Hemiptera: Psyllidae), a potential biocontrol agent of Melaleuca quinquenervia (Cav.) S.T. Blake (Myrtaceae), under quarantine. Biological Control 27: 273-292. 